\title{
Reclutamiento y remuneración de la mano de obra minera en Oruro, 1750-1810
}

Concepción Gavira Márquez

Facultad de Geografía e Historia Universidad de Sevilla

Este trabajo está centrado en el estudio de la mano de obra minera en Oruro durante las últimas décadas del período colonial. Antes de abordar el tema del reclutamiento y remuneración de los trabajadores hemos planteado algunas referencias importantes sobre la población de Oruro, sus características, evolución y desarrollo, que van a condicionar la estructura del mercado laboral. A fines del período colonial, las fuentes manifiestan un aumento de la coacción sobre la población indígena para obligarla a emplearse en la actividad minera. La crisis minera en la región y la supresión del reparto del corregidor, determinaron una disminución en la mano de obra disponible, por lo que los mineros y azogueros utilizaron métodos de compulsión para reclutar y retener a los trabajadores. Estas circunstancias, que promovieron la protesta y denuncia por parte de los trabajadores, nos conducen a cuestionar la existencia de un mercado de trabajo minero libre.

Antes de abordar las características de los trabajadores u operarios de minas de Oruro y de los centros mineros circunvecinos, ${ }^{1}$ es imprescindible aclarar que esta mano de obra era libre. Esto no quiere decir que constituyera un mercado de trabajo libre como el que se reconocería actualmente, pues como ya sabemos la Corona se encargó a través de ciertos mecanismos, como el tributo y el reparto, ${ }^{2}$ de coaccionar a la población indígena para captar sus excedentes y hacerla entrar en el circuito mercantil, bien con la venta de sus productos o de su fuerza de trabajo. Cuando utilizamos el término "libre" lo hacemos con el fin de señalar la completa libertad del trabajador en emplearse frente a la obligatoriedad del trabajo forzado, pero en este sentido tampoco podríamos generalizar que todos los trabajadores mineros en Oruro se empleasen voluntariamente en la minería durante el siglo XVIII. Sin embargo, institucionalmente lo correcto sería aludir a ese

1 Este trabajo abarca además los centros mineros ubicados en el corregimiento de Paria, en el Alto Perú. La Caja Real de Oruro tenía jurisdicción económica sobre dicho corregimiento, al que perteneció Oruro hasta 1606; en ella se registraba la plata procedente de ambos corregimientos, pero los mineros más importantes estaban asentados en la villa de Oruro.

2 Cuando nos referimos al "reparto", estamos aludiendo al reparto de mercancía que hacían los corregidores a la población indígena, y que fue legalizado a mitad del siglo XVIII. Véase Moreno Cebrián, A.: El corregidor de indios y la economía peruana en el siglo XVIII, Madrid, 1977. Y Golte, Jürgen: Repartos y rebeliones, Lima, 1980. 
calificativo, porque Oruro tan sólo gozó de trabajadores mitayos durante las dos primeras décadas del siglo XVII. ${ }^{3}$

La historiografía sobre la mano de obra de la minería andina se ha ocupado de forma más intensiva del estudio de "la mita", es decir de la concesión de trabajadores forzados a ciertos centros mineros en el siglo XVI, y que a fines del período colonial se suponía tan sólo perduraba en Potosí y Huancavelica. ${ }^{4}$ Pero durante la segunda mitad del siglo XVIII había otros centros mineros que tenían adjudicados mitayos en menor proporción. Algunos de estos beneficiarios fueron, por ejemplo, el asiento de minas de Huantajaya ${ }^{5}$ las minas de oro de Carabaya. ${ }^{6}$ Aunque, sin duda, el trabajo mitayo fue decisivo en la minería de los Andes y en especial en los centros donde fueron concedidos, a menudo se propició una focalización sobre el tema, excluyendo la importancia de otras formas de acceso al mercado de trabajo minero y la estructura de éste en otros centros andinos. En la actualidad encontramos estudios con diferentes enfoques: unos privilegian el papel del trabajo forzado, otros enfatizan la existencia de un mercado libre de trabajo en la minería colonial.?

3 Oruro nunca recibió asignaciones directas de mitayos, tan sólo se le concedió 530 mitayos que provenían de otros centros mineros en decadencia, asignación que fue cancelada por la Corona en 1618. Archivo General de Indias (en adelante, AGI), Charcas, 415, 1. III. Hay quien propone la existencia de mitayos adjudicados a Potosí que fueron llevados hasta Oruro por los azogueros potosinos hasta 1644, aunque de forma intermitente; Escobari de Querejazu, Laura: "Los extravagantes. Mano de obra en las minas de Oruro, 1606-1650”, Tiempos de América, núm. 1, Castellón, 1997, pág. 21.

4 Sobre la mita potosina: Assadourian, C. Sempat: "La producción de la mercancía dinero en la formación del mercado colonial”, en Florescano, E. (coord.): Ensayos sobre el desarrollo económico de México y América Latina (1750-1975); Bakewell, Peter: Mineros de la Montaña Roja, Madrid, 1989, y Tandeter, Enrique: Coacción y mercado, Buenos Aires, 1992.

5 Dos importantes mineros de Huantajaya tenían concedidas "dos [mitas] de a cincuenta hombres”; AGI, Lima, 1351. Informe sobre el partido de Tarapacá realizado por Antonio O’Brien, cap. 3., Tarapacá, 29 de agosto de 1765.

6 Las minas de oro de Carabaya tuvieron asignados hasta 1752, 46 mitayos de los pueblos de Huancané y Vilque, que posteriormente pasaron al cerro de Cancharani. Galaor, Isabel et. al.: Las minas hispanoamericanas a mediados del siglo XVIII. Informes enviados al Real Gabinete de Historia Natural de Madrid, Madrid, 1998, pág. 116 y 141.

7 Mientras que para la minería novohispana existe unanimidad sobre un mercado libre de mano de obra, sobre todo en el siglo XVIII, para la andina generalmente se han proyectado las circunstancias bajo las que se realizaba la explotación en el famoso cerro de Potosí. Para los siglos XVI y XVII, Bakewell hace referencia a la importancia del trabajo libre o mingado en Potosí y también a la existencia de indios de repartimientos en los centros mineros de Nueva España: Mineros de la Montaña Roja..., págs. 183-191. Sin embargo Tandeter en Coacción y mercado... enfatiza en la importancia de la renta mitaya. Fisher, Contreras y Carmagnani, en sus estudios sobre la minería peruana y chilena en el XVIII, hacen referencia a un mercado de trabajo libre, aunque no exento de presiones y quejas por parte de los empresarios, que no veían cubiertas sus demandas. En concreto, Carmagnani enfatiza el peonaje por deudas en las minas chilenas como forma de retener a los trabajadores. Fisher, J.: Minas y mineros en el Perú colonial 1776-1824, Lima, 1977; Contreras, C.: Los mineros y el Rey, Lima, 1995, y Carmagnani, M.: El salariado minero en Chile colonial, Santiago, 1963. 
Hasta el momento los trabajos realizados sobre los operarios de minas en Oruro, se han centrado en el siglo XVII. Respecto a la primera mitad del siglo, Laura Escobari ${ }^{8}$ ha puesto énfasis sobre la competencia por la mano de obra entre Potosí y Oruro, y a la coacción ejercida sobre la población indígena que se veía obligada a ausentarse del centro minero; además de proponer la existencia de mitayos en Oruro hasta 1644, aunque de forma intermitente. Ann Zulawski, ${ }^{9}$ basándose especialmente en un censo de 1683 , propone que la mayoría de los trabajadores de este centro eran forasteros que mantenían sus vínculos con la población originaria y que formaban "una mano de obra estable" y libre, que acudía a la minería como actividad complementaria a sus actividades agrícolas. Estamos de acuerdo en la importancia de este tipo de relación complementaria entre ambas actividades, pero no podemos calificar a estos empleados estacionales como trabajadores estables. Los indígenas se contrataban dependiendo de su ciclo agrícola y de sus necesidades monetarias, y a veces no coincidía con la demanda de los mineros y azogueros.

Partiendo de nuestro análisis regional hemos podido comprobar que la estructura de la mano de obra minera no era totalmente homogénea. Los centros mineros y, en concreto, el acceso a la mano de obra estaban determinados por los distintos desarrollos regionales. En el período y en el ámbito que abarca el presente estudio, se puede confirmar la existencia de un mercado de trabajo minero libre, aunque continuaban vigentes las relaciones de dominación que coaccionaban y controlaban a la población indígena para hacerla entrar o retenerla en la empresa minera. Este tipo de estrategias de presión se manifestarán con más contundencia en los momentos de crisis minera, como lo demuestran los testimonios de 1793 que analizaremos posteriormente.

Después de hacer una descripción de las diferentes labores que realizaban los distintos operarios dentro del proceso de producción, tanto en su fase extractiva como de beneficio, en este trabajo pretendemos abordar las principales características de la población que se dedicaba a esta actividad. Plantearemos la importancia del acceso a la mano de obra y los diversos medios de reclutarla, para poder evaluar la existencia de los distintos mecanismos de

8 Escobari de Querejazu: "Los extravagantes. Mano de obra...”.

9 Zulawski, A.: "Forasteros y yanaconas: la mano de obra de un centro minero en el siglo XVII", en: La participación indígena en los mercados surandinos, Comps. Harris, Larson y Tandeter. La Paz, 1987. También su libro They eat from their labor: Work and social change in colonial Bolivia. Pillsburgh, 1995. 
coacción dentro del sistema colonial. Analizaremos las distintas formas de remuneración y las compararemos con las de otros centros mineros.

\section{Trabajadores mineros}

La mano de obra empleada en el proceso de producción de plata comprendió desde el trabajo más elemental, como sería el apiri o cargador de mineral, hasta el más cualificado como el de beneficiador, de manera que esto implicaba diferentes condiciones de trabajo, sueldo y trato por parte del empresario minero, así como distinta condición social. Para obtener un mejor conocimiento de este amplio sector, realizaremos una breve descripción de las ocupaciones más importantes en el proceso extractivo y de beneficio del mineral. ${ }^{10}$

En la fase minera o extractiva el trabajo más especializado lo realizaba el barretero, que era el encargado de extraer el mineral de los frontones con herramientas simples y pesadas como las barretas o combas. La utilización de la pólvora era una labor que bien podía ser realizada por el mismo barretero o por el barrenador. El mineral extraído era transportado por el cargador o apiri desde el interior de la mina hasta la cancha o bocamina, donde el canchero o mayordomo estaba encargado de controlar las cargas extraídas, vigilar a los palliris o escogedores de mineral, y distribuir los materiales necesarios para el trabajo, como podían ser las velas o la pólvora.

También existía una demanda auxiliar de ciertos trabajos, que podían ser contratados eventualmente, o si la empresa era lo suficientemente grande permanecían como trabajadores estables. Éste era el caso del herrero (que reparaba herramientas), de los albañiles o los carpinteros que apuntalaban el sostén de las galerías.

Una vez seleccionado el mineral en la cancha-mina, era trasladado por los bajadores o cargadores que, generalmente, eran trabajadores indígenas independientes, contratados para bajar el mineral desde las minas hasta los ingenios. Las bajas, por lo general, se hacían con llamas y se solía pagar por cargas. Esto suponía un rubro bastante importante en el caso de encon-

10 Una descripción más completa de los trabajadores y de sus distintas labores se encuentra para el caso de la minería andina en García Llanos: Diccionario y maneras de hablar que se usan en las minas y sus labores en los ingenios y beneficios de los metales, La Paz, 1983. En el estudio preliminar de esta edición, Gunar Mendoza, comenta la posible visita a Oruro de García Llanos a principios del siglo XVII (pág. XXX). Un estudio de ámbito más general se encuentra en Langue, F. y Salazar, C.: Diccionario de términos mineros para la América Española (siglos XVI-XIX), París, 1993. 
trarse distanciados los ingenios de las minas, como ocurría en Oruro donde las riberas se encontraban a dos y tres leguas de las minas, o en el caso de Salinas Garcimendoza, donde no había ingenios y tenían que trasladarse hasta Poopó, costando la baja del cajón 35 pesos. ${ }^{11}$

La fase de beneficio del mineral la constituían diversos procesos que requerían de diferente cualificación del trabajador. En algunos casos el mismo azoguero administraba el ingenio, pero aun así siempre tenía una persona de confianza como el mayordomo, encargado de controlar y organizar el trabajo. El beneficiador era un trabajador cualificado y, como tal, bastante apreciado en su labor; de su preparación y pericia resultaba una mayor o menor ganancia en el trato de la amalgama y ahorro de azogue. También existía otra serie de trabajadores especializados en los diferentes procesos, como los serviris, mortiris, horneros, cernidores, y por último los repasiris. Estos últimos se encargaban de un trabajo muy duro y peligroso para la salud, removiendo con los pies la mezcla de mineral y azogue para acelerar el proceso de amalgamación. A fines del siglo XVIII, se alzaron algunas voces sensibilizadas con las trágicas consecuencias de esta labor, pero la situación no varió. Se podía utilizar animales que hiciesen este proceso, como ocurría en el caso de los ingenios novohispanos, donde desde 1777 se generalizó el empleo de mulas, pero en el caso andino su costo no entraba en los cálculos de los azogueros. ${ }^{12}$ Hasta principios de la República no se aplicaron en Potosí, de forma minoritaria, ciertas innovaciones tecnológicas que evitaban esta labor y que fueron motivadas por el ahorro de mano de obra al suprimirse la mita. ${ }^{13}$

11 Archivo Judicial de Poopó (en adelante AJ. Poopó), Minas 1700-1825. Informe del comisionado del corregidor de Paria para dar soluciones a la decadencia del asiento de minas de Garcimendoza (1770-1771). El comisionado se quejaba de la imposibilidad de conseguir bajadores para el mineral extraído y amontonado en la cancha-mina, "por lo estéril del año y no poder cargarse sus ganados que flacos se están muriendo".

12 Según Brading, en 1777 José Cornejo hizo pruebas en Taxco sobre la efectividad y economía del empleo de mulas en el repaso del mineral, siendo rápidamente aceptado por todos los mineros: Mineros y Comerciantes en el México Borbónico (1763-1810), Madrid, 1975, pág. 191. Guillermo Mira plantea que el fracaso de este invento en el Perú estaba determinado por cuestiones de costo, y alude a la posibilidad de que en Nueva España no fuese tan extendido, reduciéndose al norte donde el acceso y el precio de los animales lo hacían más rentable: "Tradición e innovación en la producción de plata americana del siglo XVIII", Proyecto N.O.A., Sevilla, 1992, pág. 125.

13 En 1836 los hermanos Ortiz inventaron y aplicaron en sus ingenios una máquina de repaso que les permitía ahorrar los salarios de los indios repasiris. Aunque firmaron una contrata con el gobierno boliviano para permitir su aplicación por los azogueros de la Ribera de Potosí, el contrato fue rescindido y no llegó a generalizarse: Platt, Tristan: "Historias unidas, memorias escindidas: las empresas mineras de los hermanos Ortiz y la construcción de las élites nacionales. Salta y Potosí, 1800-1880”. Andes. Antropología e Historia, Año 1996/97, Salta, 1996. 


\section{Población y mano de obra}

Generalmente, la población de los centros mineros estaba relacionada directamente con el momento productivo por el que pasaban, de manera que en períodos de auge, se producía un aumento de la población, no sólo con respecto a la mano de obra que esto conllevaba, sino a la reactivación de los circuitos comerciales que generaba la demanda de la actividad minera. La curva demográfica de Oruro estaba estrechamente vinculada con la curva productiva del centro minero, la cual fue algo inestable como hemos podido comprobar; pero, en todo caso, el momento de mayor auge demográfico se situó en las primeras décadas del siglo XVII, en plena alza de producción. ${ }^{14}$ Sin embargo, en 1781 se produjo una sublevación ${ }^{15}$ con características muy especiales, a la que se hizo responsable de la crisis minera que se manifestó a partir de ese año. La producción de plata que había logrado recuperarse a mediados del siglo XVIII se contrajo en más del $50 \% .{ }^{16}$ Los mineros criollos, en alianza con los indios, protagonizaron una rebelión donde se dio muerte a numerosos vecinos y comerciantes peninsulares. Más tarde la represión y detención de los mineros implicados en 1784 agravó la crítica situación por la que pasaba la minería en la región. De manera que, aunque población y producción estuviesen estrechamente relacionadas, no podemos afirmar que la producción minera determinase de forma definitiva la población del centro, pues los movimientos migratorios y la crisis que provocaron los levantamientos indígenas y su represión, afectaron directamente a la población.

En general, la mayoría de los operarios mineros en Oruro y los asientos circunvecinos eran indígenas o mestizos, y en menor proporción se encontraban los "españoles" dedicados a los trabajos más cualificados como administradores, mayordomos y beneficiadores. Precisamente era el sector

14 Un estudio sobre la producción de Oruro y la consolidación de este asiento como centro económico de la región en el siglo XVIII, se encuentra en Gavira, C.: "Oruro, centro minero del Alto Perú, 1750-1820”, Tesis doctoral inédita, Universidad de Sevilla, 1998, Cap. 1.․

15 Sobre la sublevación de Oruro existen trabajos como los realizados por Cajías de la Vega, Fernando: "La sublevación de indios 1780-1781 y la minería de Oruro", Historia y Cultura, núm. 10, La Paz, 1986. Frigerio, José: "La rebelión criolla de la villa de Oruro. Principales causas y perspectivas", Anuario de Estudios Americanos, t. LII, núm. 1, Sevilla, 1995, págs. 57-90. Cornblit, O.: Power and Violence in the Colonial City: Oruro from the Mining Renaissance to the Rebellion de Tupac Amaru (1740-1782), Cambridge, 1995.

16 La crisis minera no fue consecuencia directa de la sublevación de 1781, pero repercutió de forma importante, agravando sus manifestaciones. Gavira, C.: "Producción y crisis en Oruro a fines del siglo XVIII", Revista Metalúrgica, núm. 16, Oruro, 1997. 
indígena el más afectado por las sequías, hambrunas y epidemias que provocaban gran mortalidad, y por las consecuencias de las sublevaciones acaecidas durante el siglo XVIII y muy especialmente en su segunda mitad. Respecto a la ocupación de esta población indígena, encontramos discrepancias entre las autoridades locales. El subdelegado Vieytes advertía que los naturales eran forasteros y dedicados al laboreo de metales en su mayoría, sin embargo otro de los subdelegados, Ayarza, no era de la misma opinión:

"se equivoca el subdelegado en decir que toda está dedicada a la minería: de las diez partes juzgo yo prudente y por experiencia que las nueve están arrimadas a las haciendas y estancias de aquel partido, y la una en el laboreo de minas e ingenios, porque en éste además se emplean zambos, mulatos, cholos, y aun españoles". ${ }^{17}$

Como refiere este testimonio, y a pesar de que la mayoría de los indígenas estuviesen vinculados a la tierra, estos indios de hacienda también formaron parte de la mano de obra minera, aunque de forma estacional, dependiendo de su calendario agrícola y sus necesidades monetarias.

Respecto a los grupos étnicos de los trabajadores mineros, las fuentes manifiestan que la mayor parte estaba compuesta por indios y, en menor medida, por mestizos. Los mestizos o cholos ${ }^{18}$ parece que ocuparon cargos de más responsabilidad, intermediarios entre los indios y el administrador o mayordomo y así se encuentra manifestado en los expedientes abiertos por el levantamiento indígena. El testimonio de uno de los cabecillas aludía a la consigna de acabar con españoles y mestizos para librarse de todas las pensiones, y "que en el ingenio de Sorasora no habían de gobernar más los cholos". ${ }^{19}$ Según Brading, la mano de obra minera novohispana se distinguía por su gran movilidad, destacándose —en opinión de Lucas Alemán- una diferencia entre los centros con mayoría de trabajadores indígenas "torpes e ineptos"... "que tienen más inclinación para la agricultura", y los mulatos y mestizos, "castas ambas que se adaptan mejor a las ocupaciones que requieren energía del cuerpo y la mente". ${ }^{20}$ No hemos encontrado

17 Archivo Nacional de Bolivia (en adelante ANB), EC, año 1790, núm. 65.

18 El término cholo, aunque se puede identificar con mestizo, tiene unas connotaciones peyorativas. Bouysse-Casagne y Saignes, señalan que este término fue especialmente asignado a mestizos, criollos e indios en vías de ascenso social. Véase de estos autores: "El cholo: actor olvidado de la historia”, Unitas, núm. 5, La Paz, 1992.

19 AGI, Charcas, 601. "Testimonios del expediente y diligencias practicadas para averiguar los tumultos meditados contra Oruro". pág. 201 .

20 Brading: Mineros y comerciantes..., Informe de Lucas Alamán y Lewis Agassit, año 1826, 
respecto a Oruro ningún testimonio de descalificación del indígena para el trabajo en la minería, sin embargo, sí es constatable que la mayoría de los cargos de responsabilidad estaban en manos de los mestizos o españoles. La población negra esclava, de la que tenemos noticias, no estaba dedicada generalmente a las actividades mineras y aunque todas las familias mineras importantes tenían esclavos, no hay noticias de que ejercieran labores mineras. ${ }^{21}$

La población de Oruro, al estar compuesta de indios forasteros y yanaconas, ${ }^{22}$ era más fluctuante y variaba dependiendo de factores como el ciclo agrícola o el auge de la actividad minera. Desafortunadamente no contamos con ningún censo ${ }^{23}$ para estos años y hemos tenido que acudir a las fuentes fiscales y a otro tipo de informes, que manifiestan las consecuencias demográficas de la sublevación. La disminución de la población se debió a las muertes violentas en los enfrentamientos; a las hambrunas y a las epidemias que se padecieron después, provocadas por el abandono de los campos, por el desarraigo y la movilización que supuso el levantamiento indígena y su represión. La dificultad de cobrar los tributos en 1784 generó todo un expediente; para investigar y justificar al mismo tiempo la situación, el alcalde del Cabildo de Oruro pidió a todos los curas de la villa y repartimientos que evaluaran la disminución de la población. El cura de la iglesia de la Ranchería, barrio indígena, manifestaba lo siguiente:

"Hoy al presente es más que lamentable y deplorable el estado de ella [la villa], y del dicho ...beneficio de la Ranchería que obtengo, que causa admiración y excesiva compasión, pues sus minerales no se trabajan. Hay al mismo tiempo escasez de azogues, se halla casi sin moradores porque unos andan prófugos, otros se han ausentado a diversos lugares a buscar en qué trabajar. Los bastimentos muy escasos y en especial el pan...Que de estos miserables remanecen diariamente tres, cuatro y más muertos en las calles y canchas al rigor de la más cruel hambre, comidos de los perros, sin ser auxiliados con los santos sacramentos, ni saberse si son casados, solteros, o de qué

21 El tesorero de Oruro, Gaspar Elosu, refería en uno de sus informes a mitad del s. XVII el problema de conseguir trabajadores para las minas que "no se pueden labrar con negros ni españoles, en cuanto al trabajo, porque es tan grande que los negros no le pueden llevar por la frialdad y humedad de las minas". AGI, Charcas, 37. Gaspar Elosu a la Corona (s.f.).

22 El motivo por el cual Oruro no tenía población originaria que poseyera tierras, como era frecuente en el Alto Perú, es planteado por N. Sánchez Albornoz, como consecuencia de una sustitución total de la población, es decir por el abandono de toda la población originaria y el asentamiento de población forastera: Indios y Tributos en el Alto Perú, Lima, 1978, pág. 50.

23 El censo de 1683 refleja una población indígena masculina de 2.743 hombres, de los cuales tan sólo 139 se declararon empleados en la actividad minera, Zulawski: "Forasteros y yanaconas: la mano de obra de un centro minero...". 
patria, muriéndose repentinamente. $\mathrm{Y}$ de ellos solamente en mi dicho curato de la Ranchería, han sido sepultados en muy corto espacio de tiempo cerca de cincuenta, fuera de los que murieron en el hospital y los que se han sepultado en la misericordia de la Matriz...”. ${ }^{24}$

Otro de los factores decisivos que incidieron en esta crítica situación demográfica, fue la supresión del cargo de corregidor, y consecuentemente del reparto de mercancías efectuado por éstos y que obligaba a la población indígena a emplearse para conseguir el dinero necesario para los pagos de los productos que se repartían. Los informes enviados desde Oruro se quejaban del perjuicio que suponía la abolición del reparto para la actividad minera por ser la causa de la escasez de mano de obra. En realidad, la supresión del reparto suponía una importante merma en las cargas impositivas de los indios. El corregidor de Oruro tenía asignada la cantidad de 35.225 pesos para repartir en mercancías durante un quinquenio. ${ }^{25} \mathrm{Si}$ tomamos como referencia los 1.023 indios registrados en la retasa de 1768, les correspondería pagar al corregidor 69 pesos aproximadamente cada año por el reparto, más el correspondiente tributo. A esta cantidad habría que sumar el costo ocasional que supuestamente pagaban los indios por su exención de mitar en Potosí. ${ }^{26}$ La reducción de las obligaciones monetarias provocó una menor necesidad de entrar en el mercado de trabajo, aunque fuese de forma estacional. El subdelegado de Oruro se quejaba de que la abolición del reparto afectó de tal manera que los indios no se veían en la necesidad de contratarse para conseguir el pago de estas mercancías y ello se notó no sólo en la mano de obra disponible en Oruro, sino también en la de Carangas, desde donde se contrataban muchos trabajadores:

"el motivo de la escasez de gente no era otro que la poca de que se componía el partido, y que si en tiempos pasados no faltaba gente era porque de la abundante que hay en el de Carangas venían a buscar jornales a las riberas de éste, lo que ha cesado desde que se les dejó sólo la obligación de contribuir el tributo, pues con buscar cinco,

24 Archivo de la Corte Superior de Justicia de Oruro (adelante ACSJ. Oruro). Certificación de don Agustín de Quevedo, cura rector de San Miguel de la Ranchería. Oruro, 19 de junio de 1784.

25 AGI, Buenos Aires, 21.

26 En Oruro, al ser la población indígena yanaconas y forasteros, era excepcional el problema de mitar, pues tan sólo lo hacían o conmutaban en dinero los forasteros vinculados con su comunidad de origen. Sin embargo, en la provincia de Paria la población era mayoritariamente originaria y tenía la obligación de mitar. Encontramos el testimonio de un cacique perteneciente a la doctrina de Challapata, que decía tener un contrato con el conde de Casa Real, dueño del ingenio Agua de Castilla (donde tenían adjudicada la mita los indios de esta parcialidad), por el cual ofrecían una conmutación en dinero consistente en sesenta pesos anuales por individuo obligado a mitar. AJ. Poopó, Minas 1700-1825. 
siete o nueve pesos según la tasa de él, se echan a la haraganería a que son muy propensos y no quieren trabajar porque en buscándose para dicho tributo, su coca y un poco de maíz, nada necesitaban más según sus pensamientos, para vivir. ${ }^{27}$

Como se ha señalado, en la década de los ochenta son diversos factores los que provocaron la disminución de la mano de obra disponible; a los efectos de la sublevación y su represión, de la crisis minera y de la supresión del reparto de mercancías, se suman en los años siguientes otras circunstancias que agravaron el problema. Tal es el caso de la sequía que se produjo durante los primeros años del siglo XIX y que afectó a una extensa área del Alto Perú y provocó un gran número de muertes por hambres y epidemias ${ }^{28}$ a la que hay que añadir también una crítica situación en la actividad minera por la paralización de los ingenios por falta de agua y de azogues. ${ }^{29}$ Las quejas de los mineros y azogueros por la escasez de trabajadores, debido a la importante mortalidad provocada por las pestes que asolaron la región, fueron muy frecuentes durante los primeros años del siglo XIX. Pero sería a partir de 1810 cuando la inestabilidad política y la guerra de independencia provocaron una movilización de la población que repercutió de manera decisiva en la actividad minera. Estos años se sumaron acontecimientos de diversa índole que causaron una gran inestabilidad tanto en la villa como en la región. En 1809 los comunarios de Toledo (Paria) amenazaban con levantarse. Esta amenaza aterrorizó a los vecinos de Oruro, que aún recordaban la violencia desatada en la villa en 1781, y pidieron ayuda para protegerse. Desde Cochabamba se trasladaron efectivos para velar por la seguridad de los vecinos, pero las circunstancias exigieron a esta tropa abandonar urgentemente Oruro para socorrer a Potosí, amenazada por el ejército rebelde de Buenos Aires. Los vecinos de la villa huyeron ante el temor de una invasión indígena. La deserción de los vecinos de la ciudad llegó a tal punto que el presidente de la Audiencia mandó publicar un bando para disuadir con graves penas a los fugados de la villa. El Cabildo se negó a publicar el bando por considerarlo una medida "extratemporánea" e inútil. Esta medida llegó bastante tarde, pues según los tes-

27 ANB, Minas, t. 131, núm. 13. Carta del subdelegado Simón Romano a la Audiencia de Charcas. Oruro, 9 de octubre de 1792.

28 Los caciques de la doctrina de Challapata se quejaban de las dificultades del cobro del tributo y del envío de mitayos a Potosí, debido a las muertes por "la peste y hambre que acaeció por la escasez de lluvias”. AJ. Poopó, leg. Minas 1700-1825, año 1807.

29 Un estudio sobre el problema de la sequía y la falta de azogue en Potosí se encuentra en la obra de Tandeter: Coacción y Mercado, págs. 263-266. 
timonios, "las tres de las cuatro partes de la plebe han emigrado según se nota en el público aspecto y silencio de las calles". ${ }^{30}$

\section{Reclutamiento de la mano de obra}

Los problemas planteados a los mineros a la hora de reclutar la mano de obra, podían estar determinados, bien por la escasez de población que no cubría la demanda de trabajadores, o bien porque la población mayoritariamente indígena asentada en la región, no tenía la necesidad de emplearse voluntariamente en el trabajo minero. Toda esta "máquina" 31 —como denominaba el subdelegado de Paria a los mecanismos impuestos por el sistema colonial - no fue siempre capaz de abastecer la demanda de mano de obra de los empresarios mineros. Dos factores importantes, a los que ya hemos aludido, agravaron la situación en la región a la hora de conseguir trabajadores: la supresión del reparto de mercancías efectuado por los corregidores, y la disminución de la mano de obra minera que se desplazaba a distintos centros dependiendo del auge productivo. Las estrategias para atraer y retener a los trabajadores fueron muy diversas, sobre todo porque también había que contar con otro factor importante: la competencia.

La competencia por la mano de obra entre los distintos centros mineros benefició al sector de trabajadores más especializados, compuesto por un grupo de población flotante que se desplazaba hasta los distintos centros en que se producían boyas interesantes, y que propiciaban buenos salarios y partidas de mineral como atractivo. Sin embargo, otro grueso de la mano de obra era reclutado entre la población local asentada. En Oruro y los asientos circunvecinos, los mineros y azogueros se valieron en muchas ocasiones de recursos coactivos para conseguir trabajadores, bien a través de los mecanismos legales como pudieron ser los cargos de corregidores, alcaldes y subdelegados, ${ }^{32} \mathrm{o}$ bien a pesar de ellos, utilizando la violencia. Si

30 Acta de Cabildo del 19 de noviembre de 1810, recogida por Ávila, Beltrán: Historia del Alto Perú en 1810, Oruro, 1918.

31 AGI, Buenos Aires, 434. Expediente, año 1784. Carta del subdelegado de Paria al presidente de la Audiencia de Charcas. Poopó, 8 de julio de 1784. Así entendía el subdelegado el sistema: "Este partido es menester que V.E. comprenda que tiene sobre sí todas las pensiones que no son comunes en los demás, como regularmente son: tributos, mita y tambos. Y si falta el giro de las minas como está sucediendo pierde indispensablemente su concierto toda esta máquina".

32 Generalmente los corregidores o subdelegados negociaban con los caciques o alcaldes indios el envío de trabajadores a las minas e ingenios. Por ejemplo en 1792, ante la queja del azoguero Juan Arriluciaga por no tener suficientes operarios en su ingenio, el subdelegado reunió a varios alcaldes indios y les preguntó "cómo no proporcionaban los indios suficientes”. ANB, Minas, t. 131, núm. 13. 
en un principio el auge de la minería pudo permitir la atracción de la mano de obra por medio de altos salarios y partidas de mineral, en el período posterior, una vez pasada la abundancia del auge, los empresarios mineros emplearon otras estrategias.

La población indígena campesina solía acudir a la minería como fuente de recursos para conseguir el dinero con el que pagar sus obligaciones tributarias. Pero tan sólo acudía de forma esporádica, según sus necesidades y su calendario agrícola. Este sector de la población fue el más presionado para que se emplease en las minas e ingenios cuando era acuciante la necesidad de mano de obra. Existen expedientes que describen las distintas formas de reclutar a esta población asentada en las haciendas aledañas a los centros mineros.

En esta documentación, generalmente expedientes abiertos por el protector de naturales ante la Audiencia de Charcas, encontramos numerosas referencias sobre cómo los pongos de haciendas eran compelidos para trabajar en los ingenios o prestar auxilios. En 1793 los indios de la hacienda de Cantomarca (Paria) fueron obligados a trabajar por el mayordomo "a fuerza de un chicote que traía pendiente de un látigo", ${ }^{33}$ en el ingenio que se encontraba ubicado en la misma hacienda. Otro de los casos que llegaron hasta la Real Audiencia denunciaba el engaño con que fueron obligados unos indios carboneros por el regidor Miguel Urquieta, a llevar carbón hasta su fundición de estaño en Huanuni, aprovechando que eran pongos de una hacienda que había arrendado su hermano Antonio Urquieta. Éstos se quejaban: "que nos hace traer carbón de por fuerza contra nuestra voluntad dándonos vales, engañándonos en la romana del carbón que llevamos por vernos indios pusilánimes...". ${ }^{34}$

En el expediente abierto en 1793 se pedía una investigación que comprendiese los testimonios de todos los trabajadores de los ingenios de las tres riberas, Sorasora, Sepulturas y Poopó (Paria). La primera pregunta que se propuso a los testigos nos parece bastante significativa:

"Digan si saben y les consta que los operarios, mandones y mayordomos de dichos ingenios nos maltratan cruelmente con el pretexto de llevarnos forzadamente al penoso trabajo de los buitrones sin darnos ya lugar para labrar, cultivar y sembrar nuestras sementeras, ni las que son de los patronos". ${ }^{35}$

33 ANB, Minas, t. 131, núm. 16.

34 Ibídem, t. 131, núm. 12, año 1762.

35 Ibídem, núm. 16. 
Todas las respuestas de los testigos afirmaban este comportamiento, especificando:

"cómo los sitados mayordomos y mandones, salen a los campos, y de allí conducen a los indios a dichos ingenios, sean de este paraje, o caminantes, o los que están en las chacras, a todos y a cuantos pueden los llevan a fuerza de chicotazos, amarrados y arrastrados hasta entregarlos en el buitrón". ${ }^{36}$

En todos los testimonios encontramos una referencia continua y específica al "penoso trabajo en el buitrón". ${ }^{37}$ Los indígenas compelidos eran destinados a realizar una de las labores más duras de todo el proceso de beneficio, como era el repaso. Éste consistía en remover con los pies la mezcla de azogue y mineral para acelerar el proceso de amalgamación. Esta mezcla, en ocasiones, era tan perjudicial que los mismos indígenas se negaban a realizar el trabajo, como ocurrió en 1840 en Salinas de Garcimendoza, "pues que la calidad de los metales es tal que no hay repasiri que sufra una semana de trabajo sin que se le hagan pedazos los pies, como es constante a todo aquel vecindario". ${ }^{38}$

Como hemos podido comprobar a través de los expedientes y los informes mandados a la Audiencia, los indios de haciendas fueron compelidos al trabajo en los ingenios de forma violenta cuando su calendario agrícola les requería en el trabajo de la tierra. Puede deducirse entonces, que este grupo de tributarios tan sólo se empleaba como operarios mineros estacionalmente con el fin de recaudar el dinero necesario para el pago de sus obligaciones impositivas, y mientras su actividad principal que les proporcionaba la subsistencia se lo permitía ${ }^{39}$ Se plantea, en este caso, la misma situación que la estudiada por Tristan Platt en la región de Lipez,

36 Ibídem.

37 Buitrón: "receptáculo de madera o piedra en que se hacía la amalgama del azogue y la plata, dividido en seis compartimientos llamados cajones, todo sobre un suelo de bóveda para poder dar fuego por debajo". Este procedimiento se efectuó en el siglo XVI, posteriormente continuó llamándose buitrón a los cajones donde se realizaba la amalgama en frío, García Llanos: Diccionario y maneras de hablar..., pág. 14-15. (Mendoza: Estudio preliminar...) Véase Langue y Salazar: Diccionario de términos mineros...

38 Defensa que presentó el prefecto de Potosí, Mariano Zilveti, ante la Corte Suprema, sobre la máquina de repaso inventada por los hermanos Ortiz , puesta en práctica en sus ingenios en Potosí, Garcimendoza y Guariguari. Platt: "Historia unidas, memorias escindidas...”, pág. 174.

39 Por ejemplo, Pedro Mamani, indio tributario de Sacaca, dijo que, para pagar una deuda con su cacique, fue a trabajar 15 días en el ingenio de José Cazaos y como no le pagaron su jornal, se quejó al alcalde de Sorasora que intercedió por él, pero cuando fue a cobrar recibió una paliza por parte del mayordomo del ingenio. ANB, Minas, t. 131, núm. 16. 
es decir, un desfase entre la economía indígena y el mercado interno construido en torno a la producción minera. ${ }^{40}$ Aunque no de forma tan específica, como en el caso de los llameros de Lipez requeridos para la baja del mineral, los indios de haciendas tenían el recurso del trabajo en la minería, es decir, su acceso al mercado de trabajo, integrado dentro de un conjunto mayor de estrategias reproductivas que en este caso estaban determinadas por el calendario agrícola. Y como referimos anteriormente, las necesidades de dinero de la población indígena disminuyeron al suprimirse el reparto y, por tanto, su necesidad de emplearse como operario en las minas e ingenios.

La protesta que hizo en 1793 el protector de naturales, pidiendo a los dueños de minas e ingenios que no obligasen a los indios de hacienda a trabajar en los segundos porque de ello "resulta el abandono y exterminio de sus familias", ${ }^{41}$ nos podía hacer pensar en una competencia por la mano de obra entre hacendados y mineros, pero conociendo a los dueños de haciendas y sus actividades mineras, podemos deducir que éstos utilizaban a los indios de hacienda para el trabajo en las minas e ingenios en caso de necesidad. Es decir, el minero o azoguero, para asegurarse trabajadores, se convertía en hacendado o en arrendatario de tierras. En el estudio demográfico que realiza O'Phelan sobre los trabajadores mineros de Hualgayoc a fines de la colonia, también consta la procedencia de operarios de las haciendas de la localidad. ${ }^{42}$ Como ocurría en Oruro, los mineros sustraían de las haciendas los trabajadores cuando no era cubierta la demanda de manera voluntaria. ${ }^{43}$

La actitud violenta de los mayordomos y mandones, a voluntad de los dueños de ingenios, para reclutar mano de obra, parece que fue más allá de las haciendas aledañas. Según los expedientes relativos a los abusos, se

40 Platt, Tristan: "Calendarios tributarios e intervención mercantil. La articulación estacional de los ayllus de Lipez con el mercado minero potosino (siglo XIX)”. En La participación indígena en los mercados surandinos.

41 ANB, Minas, t. 131, núm. 16.

42 O'Phelan, Scarlet: "Vivir y morir en el mineral de Hualgayoc a fines de la Colonia", Jahbuch Für Geschichte Lateinamerika, vol. 30, año 1993. Esta autora considera que la hacienda, a este respecto, puede ser vista como una reserva de mano de obra.

43 Los problemas por la escasez de trabajadores en el centro minero de Hualgayoc, que tampoco disponía de mitayos, planteó un proyecto donde se tuvo en cuenta la estrecha vinculación de los indígenas con la tierra. El obispo de Trujillo y los mineros pretendían crear un asentamiento alrededor de las minas donde se le ofrecería tierra a los forasteros a cambio de su prestación laboral en la actividad minera. Este proyecto no consiguió llevarse a cabo. Véase Contreras: Los mineros y el Rey..., pág. 98. 
practicaron levas obligatorias o expediciones para conseguir trabajadores. Así se manifestaba no sólo en los testimonios presentados por los indígenas, sino que también quedaba reflejado en las preguntas que en su defensa expuso el azoguero José Cazaos, el cual tenía abierto un expediente por malos tratos a sus trabajadores:

"Ytem, digan si saben que a alguno que traiga materiales, si es voluntariamente, y si les pago inmediatamente en plata efectiva, por cuya razón casi nunca salen mis mayordomos a arcar $^{44}$ a excepción de una vez al año como dicen, y esto sin estrépito". ${ }^{45}$

Curiosamente, en la misma pregunta se está confirmando la práctica de salir a hacer levas de indios para emplear en los trabajos menos cualificados y remunerados de los ingenios. Uno de los testimonios presentados por los indios, manifestaba cómo se hacían estas levas sin discriminación ninguna y utilizando el engaño, siendo bastante significativo que aludan a la máxima autoridad, el rey, para justificar su acción:

"También atajan a los indios que traen víveres y comestibles a la villa de Oruro, los llevan al ingenio y se quedan sus cargas en el camino a cuyo hecho se les pierde, como ha oído decir, y lloran a sus dueños pero ellos sin más apoyo que decir son mandados y que es el ingenio del Rey, y que por él se trabaja....". ${ }^{46}$

Estas prácticas en ningún momento estuvieron respaldadas por las altas autoridades coloniales como ocurrió —según Fisher — ${ }^{47}$ en Perú, cuando virreyes como Croix en 1788 y Gil, en 1793, hicieron los arreglos necesarios para proveer de trabajadores a ciertos mineros, aunque bajo la denominación de "socorro" para evitar la palabra mita. En el caso de Oruro, las autoridades locales estaban al corriente de estas levas forzosas, entre otras cosas, porque los mineros y azogueros ejercieron de corregidores, subdelegados y constituyeron generalmente el Cabildo, ocupando puestos como los de alcaldes, que suponían jurisdicción en primera instancia en asuntos civiles y criminales. Así lo manifestaba el juez comisionado, Manuel Delgado, en un informe a la Audiencia el año 1790:

44 Según el Diccionario de Langue y Salazar, Harcar: "atajar, impedir o detener lo que va, corre o sale en animales y personas y aún obras y negocios". García Llanos relaciona este término con la siega en Castilla y lo determina como atajar o acorralar. Diccionario y maneras..., pág. 54.

45 ANB, Minas, t. 131, núm. 16.

46 Ibídem.

47 Fisher: Minas y mineros..., pág. 188. 
"Constándole a ciencia cierta al mismo contador que por la escasez de gente, cada dueño de ingenio acceda por ello a la rapiña hasta valerse de jueces para su recluta" ${ }^{48}$ El minero Juan Arriluciaga recurría a la Audiencia de Charcas en 1792, pidiendo que "se compelan a 25 ó 30 indios urus de la laguna de Challacollo" para trabajar en su ingenio, prometiendo buen trato y paga efectiva. Su petición fue respaldada por el subdelegado de Oruro, Simón Romano. Pese a ello, la respuesta de la Audiencia fue negativa diciendo que debía arreglar sus necesidades "sin pretensión a derecho y justicia". ${ }^{49}$

La competencia por la mano de obra se producía entre los mismos dueños de minas e ingenios, y también entre los diferentes centros mineros. En 1797, llegó hasta la Audiencia una queja de los azogueros por la actuación del subdelegado de Oruro, al cual acusaban de estar reclutando barreteros y peones de minas para los mineros de La Paz, en concreto para el descubrimiento de "un cerro con el sobrenombre del Poderoso". Dijeron que el subdelegado se aprovechó de "la oportunidad de la noche y el día feriado", para escoger los operarios más cualificados con engaños y la seducción de mejor fortuna, retenerlos y enviarlos a La Paz. Pretendían que la Audiencia tomase una determinación para evitar lo ilegal de tal medida basada en el "socorro y avíos" adelantados a los reclutados, "porque gozando los indios la atención y privilegios de menores y miserables necesitan otra solemnidad, como porque en virtud de dicho contrato no quedan hábilmente obligados como en caso preciso se les hará ver a un tiempo". ${ }^{50}$ Sin embargo, ellos mismos bajo otras circunstancias alegaban este tipo de contrato y adelantos como válidos y suficientes para reclamar a los trabajadores. El azoguero Solano Polo acudió en 1790 ante el corregidor, denunciando que a pesar del adelanto en dinero efectuado a ciertos operarios, éstos no acudían allí porque estaban trabajando en la mina y fundición de José Domingo Salamanca, el cual "los coarta e impide la voluntad teniéndolos en su mina y fundición de Huanuni con opresión, de suerte que, por más que aspiran a satisfacer sus deudas, no pueden conseguirlo". El corregidor notificó a Salamanca que debía dejar libre a los trabajadores, ${ }^{51}$ por tanto, se respetaba formalmente el adelanto realizado a los operarios como si fueran contratos legales.

48 ANB, Minas, Complemento, t. 151, año 1790.

49 Ibídem, t. 131, núm. 13, año 1792.

50 Ibídem, t. 90, núm. 12.

51 ACSJ. Oruro, año 1790. 
Los adelantos de dinero, como forma de atraer y sujetar a los trabajadores, tenían una contrapartida que consistía en la fuga del trabajador hacia otro lugar, o emplearse con otro patrón que le ofreciera mejores condiciones. Las Ordenanzas de Minería de Nueva España, aplicadas en Perú y Chile, tenían estipulado el derecho de los interesados a buscar y perseguir al trabajador para cumplir con el contrato. Al parecer, esta medida, que representaba una clara defensa de los intereses de los patronos como forma de retener la mano de obra mediante la deuda, ya estaba estipulada en la Recopilación de Leyes de los Reynos de Indias. ${ }^{52}$

No podemos evaluar la proporción de trabajadores que eran reclutados de forma coactiva, pero sí podemos considerar la importancia de estas formas de reclutamiento que afectaron mayoritariamente a la población indígena asentada en las haciendas locales, y que fueron destinadas, por lo general, al trabajo más duro de los ingenios. Los testimonios nos dejan constancia de la existencia de mecanismos para captar y retener la mano de obra que iban más allá de las instituciones del propio sistema de dominación colonial. Además de la compulsión violenta o amenazas, otra de las prácticas que se consolidaría con el tiempo sería el endeudamiento, que en muchos casos encubría abusos y sobreprecios de los productos, como veremos a continuación.

\section{Diferentes formas de remuneración: mineral, dinero y productos}

La forma y cantidad de pago por el trabajo minero no estaba reducida exclusivamente al salario. En Oruro, al igual que en otros centros mineros coloniales, las distintas formas de remuneración comprendían principalmente dinero, especies y, en ciertos casos, los trabajadores dedicados a las labores extractivas también se llevaban una parte de mineral, concertada previamente con el dueño de la mina. Los salarios variaban de una empresa a otra, según la rentabilidad de la misma, la escasez de trabajadores o la cualificación del operario.

Para abordar el salario de los trabajadores en una labor de mina tomaremos como ejemplo el caso particular de la mina San José. ${ }^{53}$ La elección de esta mina no viene determinada por su representación como empresa

52 Libro VII, Título VII, Ley XIV.

53 ANB, Minas, t. 149, año 1765-1766. 
minera típica de Oruro. Desgraciadamente, no contamos con datos suficientes para confirmar hasta qué punto podríamos tomar este caso como modelo, pero, aun así, nos parece un ejemplo bastante ilustrativo, por la cantidad de información que nos muestra. Basándonos en las cuentas de gastos semanales, donde el encargado o administrador anotaba todos los gastos producidos por salarios e insumos, analizaremos la forma y cantidad de pago, el número de trabajadores y el costo que representaba para la empresa.

El período que comprende estas anotaciones es de seis meses, 26 semanas, desde julio de 1765 hasta enero de 1766. En el cuaderno de cuentas se presenta un resumen de los gastos por semanas, distinguiendo a los trabajadores en tres grupos: barreteros, apiris y palliris. El trabajador recibía su salario según los turnos o mitas trabajadas, de manera que el pago semanal dependía de las jornadas de trabajo realizadas, que no tenían por qué ser las seis correspondientes de lunes a sábado. Los jornales establecidos a los barreteros, apiris y palliris eran de cuatro reales por mitas ${ }^{54}$ indistintamente. No aparece información sobre otro tipo de retribución en mercancías o mineral, pero encontramos referencias en el cuaderno al envío de coca y pan hasta las instalaciones, por lo que suponemos la existencia de una pulpería. Como se muestra en el cuadro siguiente, se presenta un progresivo aumento en los gastos semanales que viene determinado por el aumento de trabajadores. La primera semana el grueso mayor de los trabajadores lo representaban 6 barreteros, 9 apiris y 4 palliris, en cambio las últimas semanas registradas aumentaron hasta 21 barreteros, 25 apiris y de 10 a 12 palliris. También observamos que, si al principio de este período, los turnos o mitas cobrados giraban en torno a 5 o 6 por barreteros y apiris y, algo menos, los palliris; en las últimas semanas, se intensificaron las jornadas y aparecen registrados de forma frecuente algunos trabajadores que cobran por 7 u 8 mitas e incluso, en ocasiones, por 11 mitas semanales.

Además del salario de los trabajadores de base, están recogidos otros operarios con distintas calificaciones, como el herrero y el arreador, encargado de que se cumplan las faenas, que comenzaron cobrando 4 pesos semanales y aumentaron hasta 7 pesos en las últimas semanas. Por último, el canchero, quien estaba encargado de pagar todos los sueldos y gastos anotándolos en este cuaderno para presentar al dueño de la mina.

54 Ibídem. Las jornadas o turnos trabajados son designados con el término mita. 


\section{CuAdro 1}

CUENTAS SEMANALES DE LA MINA SAN JOSÉ, 1765-1766

\begin{tabular}{lclccc} 
Semanas & Salarios & $\%$ & Insumos & $\%$ & Total \\
\hline $29-07-1765$ & 69 & $88 \%$ & 8,3 & $12 \%$ & 70,3 \\
$05-08-1765$ & 94,2 & $85 \%$ & 15,7 & $15 \%$ & 110 \\
$12-08-1765$ & 93,1 & $87 \%$ & 14 & $13 \%$ & 107,1 \\
$19-08-1765$ & 156,2 & $89 \%$ & 18,1 & $11 \%$ & 174,3 \\
$26-08-1765$ & 118 & $88 \%$ & 16 & $12 \%$ & 133 \\
$02-09-1765$ & 133,7 & $88 \%$ & 18,1 & $12 \%$ & 152 \\
$09-09-1765$ & 122,1 & $89 \%$ & 14 & $11 \%$ & 136,1 \\
$16-09-1765$ & 101,1 & $87 \%$ & 13,6 & $13 \%$ & 114,7 \\
$23-09-1765$ & 124,1 & $88 \%$ & 16 & $12 \%$ & 140,1 \\
$30-09-1765$ & 133,6 & $89 \%$ & 17,3 & $11 \%$ & 151,1 \\
$07-10-1765$ & 132,5 & $85 \%$ & 23 & $15 \%$ & 155,5 \\
$14-10-1785$ & 133,4 & $87 \%$ & 20,1 & $13 \%$ & 153,5 \\
$21-10-1765$ & 145,2 & $83 \%$ & 29,5 & $17 \%$ & 174,7 \\
$28-10-1765$ & 101 & $88 \%$ & 13,6 & $12 \%$ & 114,6 \\
$04-11-1765$ & 162 & $89 \%$ & 19,4 & $11 \%$ & 181,4 \\
$10-11-1765$ & 178,5 & $86 \%$ & 27,2 & $14 \%$ & 206,7 \\
$18-11-1765$ & 216,2 & $87 \%$ & 32 & $13 \%$ & 248,2 \\
$25-11-1765$ & 221 & $61 \%$ & 27,7 & $8 \%$ & 363,1 \\
$02-12-1765$ & 180 & $84 \%$ & 35,4 & $16 \%$ & 215,4 \\
$09-12-1765$ & 225,4 & $86 \%$ & 35,5 & $14 \%$ & 261,1 \\
$16-12-1765$ & 193,7 & $83 \%$ & 37,6 & $17 \%$ & 231,5 \\
$23-12-1765$ & 153,3 & $88 \%$ & 19,6 & $12 \%$ & 173,1 \\
$30-12-1765$ & 176,2 & $85 \%$ & 32,4 & $15 \%$ & 208,6 \\
$06-01-1766$ & 203 & $86 \%$ & 31,2 & $14 \%$ & 236,2 \\
$13-01-1766$ & 214 & $84 \%$ & 41 & $16 \%$ & 255 \\
$20-01-1766$ & 210,1 & $83 \%$ & 42,3 & $17 \%$ & 252,4 \\
& & & & &
\end{tabular}

Fuentes: ANB, Minas, t. 149, año 1765-1766. 
También aparecen, de forma esporádica, algunos pagos a trabajadores ocasionales que eran requeridos para necesidades puntuales, éste era el caso del albañil y sus peones. En la semana del 25 de noviembre, que fue atípica por incluir entre los gastos el pago de la visita de minas que consistió en 96 pesos, se registraron los gastos por 4 chivatos. Bajo este concepto podría recogerse, bien los odres con el cual se extraía agua de las minas o bien los trabajadores encargados de realizar esta labor.

El costo por mano de obra — según el cuadro anterior - representaba una media aproximada del $86 \%$ del total de los costos semanales. Hay que advertir que ciertos gastos, como el abastecimiento de coca y el pan, no fueron recogidos en el cuaderno. De todas formas, partiendo del ejemplo concreto de esta mina, nos parece importante señalar el alto costo que representaban los gastos por mano de obra, siendo de suponer que los empresarios mineros intentasen por todos los medios reducir, dentro del máximo posible, los costos por este concepto. Es evidente que, en gran medida, la explotación minera recaía sobre la mano de obra y su importancia con respecto a otros rubros son abismales. Los gastos por herramientas e insumos en este caso eran mínimos..$^{55}$

Si comparamos estos salarios con otros centros, observamos que en Hualgayoc (Perú), según el estudio de Carlos Contreras, los salarios de barreteros y apiris eran casi equivalentes, aunque el denominado mayordomo recibía de siete a ocho pesos semanales, mientras que el canchero de la mina San José cobraba un salario mucho más alto. ${ }^{56}$ En las cuentas de los gastos de la mina potosina "Labor de Medina", en 1775, encontramos que los barreteros, que solían ser mingas (trabajadores contratados), recibían entre seis y siete reales por turno, al igual que los apiris mingas. La referencia encontrada en este documento como salario del "minero", ${ }^{77}$ se refiere al mayordomo o encargado de la mina, al cual se le pagaba 11 pesos semanales. ${ }^{58}$ Las diferencias entre los sueldos de los distintos centros parecen más considerables entre los trabajadores más cualificados. Claro que

55 En el caso de Oruro los costos por arrendamiento de las instalaciones mineras eran poco significativos comparados con Potosí. Este tema ha sido tratado por mí en "Producción y crisis en Oruro...".

56 Contreras: Los mineros y el Rey..., pág. 76.

57 Tandeter los denomina como "supervisores de los trabajadores de las minas", a quienes los azogueros solían entregar las pulperías o "chicherías" bajo arriendo: "Los trabajadores mineros y el mercado”, Anuario. Archivo y Biblioteca Nacionales de Bolivia, Sucre, 1996, pág. 61.

58 Archivo Histórico de Potosí. Casa Nacional de Moneda. Expedientes de Gobierno e Intendencia, núm. 381. 
ello tiene mucho que ver con la capacidad de la empresa minera. ${ }^{59}$ Cuando se trataba de una mina en total rendimiento y con muchos operarios, la competencia y responsabilidad del mayordomo o canchero sería mayor y, por lo general, recibiría un salario más alto. Esto ocurrió en la mina San José, cuando se intensificaron las labores y aumentaron los trabajadores, también se elevaron los salarios del herrero y del arreador.

En el virreinato de Nueva España, el salario también variaba de un centro a otro y dependiendo de la empresa. Aunque se pagaba de forma generalizada un salario de 4 reales, el verdadero atractivo - según Brading - lo constituía el partido. ${ }^{60}$ En Oruro, el equivalente al partido era denominado doblas. En principio se trataba de un concierto con el dueño para trabajar la mina sábados y domingos, pero afirma García Llanos que se convirtió en una costumbre durante toda la semana. No sabemos, de forma certera, las condiciones de este acuerdo que generalmente no quedaba registrado por escrito sino que se hacía verbalmente. Este mismo autor hace referencia al valor de las doblas, "muchas de éstas que han valido a quinientos pesos y algunas a mil y a más..."; ${ }^{61}$ pero habría que tener en cuenta que esta descripción se está refiriendo a principios del siglo XVII, en pleno auge productivo en Oruro. Godoy, en su Relación de 1607, no recoge este término, aunque alude a una entrega de mineral como forma de atraer a los trabajadores, "además de este jornal les dejaba llevar algunas corpas de metal que las más veces valen el doble del jornal". ${ }^{2}$ También deja constancia el visitador de que este concierto se convirtió en "hecho general", atrayendo a todo tipo de gente a rescatar el mineral de los indios. En el caso de no tener permiso o autorización del dueño, es cuando se consideraba juqueo, es decir, robo. Esta costumbre, que representaba una participación de los trabajadores en los medios de producción, constituía todo un atractivo para la mano de obra y también era una forma de pago que permitía reducir el costo del salario.

El monto de mineral concertado que se le atribuía al trabajador, llámese dobla, partido o pepena, era muy importante en cuanto suponía una for-

59 Arduz Eguía propone, según un documento anónimo de 1759, los siguientes salarios en el Cerro de Potosí: los mitayos cobraban 4 reales por jornada y los voluntarios 6 reales, "los mineros inteligentes, sobrestantes y directores ganan semanalmente 8, 10, 12 o más pesos...": Ensayos sobre la historia de la minería altoperuana. Madrid, 1984, pág. 106.

60 Brading: Mineros y comerciantes..., pág. 202.

61 García Llanos: Diccionario y maneras..., pág. 42.

62 Godoy, Felipe de: "Relación del asiento, minas y población de San Felipe de Austria, llamados de Oruro", Boletín de la Oficina Nacional de Estadísticas, año VIII, La Paz, 1912, pág. 438. 
ma de remuneración a veces más interesante que el propio salario y permitía al operario no estar a expensas de un salario que podía verse reducido por el pago en especies. Este sistema supuso que en las minas más pequeñas, los trabajadores, preferentemente los del interior de la mina, se convirtieran en una especie de socios del propietario. Esta situación ha sido determinante para no considerar a los operarios de minas, que trabajaban bajo estas condiciones, como simples proletarios, ya que compartían la producción. ${ }^{63} \mathrm{El}$ trabajador solía vender el mineral a los rescatiris, a los beneficiadores particulares, o al propio dueño de la mina. En caso de tratarse de un mineral de alta ley, esta operación representaba un ingreso bastante importante. En Oruro, especialmente en este período, no tenemos muchas referencias a esta forma de remuneración, pero habría que tener en cuenta que la crisis minera, a partir de la década de los ochenta, limitó, en gran medida, el concierto de doblas a los trabajos puntuales de ciertas vetas que se fueron descubriendo. De todas formas, nos parece bastante significativo el haber encontrado estipulado en algunas cláusulas de compañías que no se permitiría este tipo de concierto con los trabajadores. Esta tendencia a reducir o suprimir este tipo de remuneración en mineral fue bastante generalizada en las minas novohispanas durante la segunda mitad del siglo XVIII. Los conflictos suscitados por esta tendencia, que respondió, según la mayoría de los analistas, al proceso de racionalización de la empresa minera, ${ }^{64}$ promovieron grandes disturbios en algunos centros novohispanos.

Otro de los sistemas más comunes establecidos en el trabajo extractivo principalmente, era el trabajo a destajo, es decir se pagaba por las cargas de mineral sacadas a la superficie. Este sistema era bastante rentable para el dueño y muy arriesgado para el trabajador, que podía tener la desventaja de encontrar zonas bastante duras de trabajar que requerían mayor esfuerzo y tiempo. Generalmente, el dueño de la mina solía pagar algunos insumos como la pólvora y las guías. Las condiciones establecidas en esta forma de trabajo aumentaban los riesgos de accidentes en el interior de la mina porque los operarios pendientes de sus intereses económicos no prestaban atención a la seguridad, ni dedicaban su tiempo a reparar, fijar sueltos o desprenderse de las cajas para desalojar los caminos. Éste fue el moti-

63 Sobre este tema son más frecuentes los estudios basados en los trabajadores y minas del virreinato novohispano. Véanse Velasco, Cuauhtémoc: "Los trabajadores mineros en la Nueva España, 1750-1810", en La clase obrera en la historia de México, vol. II, "De la colonia al imperio". Compilador Enrique Florescano. México, 1980. Y Hadley, Phillip L.: Minería y sociedad en el centro minero de Santa Eulalia, México, 1979.

64 Velasco: "Los trabajadores mineros...", pág. 349. 
vo aducido en un expediente abierto por la muerte de un trabajador en una de las minas de Manuel Herrera, el cual responsabilizó a los trabajadores de las malas condiciones de la mina. Herrera explicó que el sistema de trabajo en esta mina era el llamado "por puñeros, comprando los metales de los indios". ${ }^{65} \mathrm{El}$ propietario compraba el mineral extraído a los indios, los cuales, pendientes de sacar el máximo de mineral, no se encargaban de la seguridad en el interior de las minas. Esta forma de explotación era muy rentable para el dueño de la mina, el cual, además, no se hacía responsable de los accidentes.

Los sistemas de trabajo en la explotación de las minas eran mucho más variados y complejos que los establecidos en las plantas de beneficios. La existencia de pequeñas y medianas explotaciones que se trabajaban bajo distintos conciertos con los trabajadores hace difícil generalizar a los operarios de minas en cuanto a sueldos y relación con los medios de producción. En centros más alejados o abandonados, como era el caso de Salinas de Garcimendoza a fines del siglo XVIII, la mayoría de las minas registradas eran propiedades de los indios originarios de las comunidades vecinas. Estas pequeñas explotaciones pudieron ser trabajadas familiarmente o por medio de compañías, pero desgraciadamente no tenemos datos precisos. ${ }^{66}$

Respecto a los trabajadores de ingenios, los operarios más cualificados, administradores, mayordomos y beneficiadores cobraban los salarios más altos. Éstos realmente se podían considerar como los integrantes del mercado libre de trabajo, se beneficiaban de los períodos de escasez de mano de obra aprovechándose para subir las distintas ofertas de los empresarios. Sabemos que el beneficiador Lunita, aun teniendo una propuesta del azoguero Manuel Herrera de 30 pesos semanales, "fue a Oruro a disponer el negocio, a ver si le adelantan el salario, o para ponerse en almoneda del que más diere" ${ }^{67}$ Los mineros, a veces, se convirtieron en víctimas de sus mecanismos para retener la mano de obra. El trabajador podía conseguir un

65 ANB, Minas, t. 131, núm. 9.

66 AJ. Poopó, Minas 1700-1825, año 1787. Peticiones para la adjudicación de minas en el asiento de Salinas de Garcimendoza. Otro de los informes sobre la población de Paria alude a las actividades de los naturales de Salinas de Garcimendoza como dedicados al giro del comercio de la sal, y "algunos al decadente ejercicio de trapicheros de metales de plata de dicho pueblo".

67 AGI, Charcas, 605. Cartas extraídas de los papeles embargados a Diego Flores. En una carta de Manuel Herrera se cuentan las negociaciones con el beneficiador Lunita, que pide cinco pesos más que el beneficiador actual, lo cual no es impedimento a juzgar por su comentario, "la diferencia sólo puede consistir en cinco pesos, pero si lo hace bien no quieren decir nada los dichos pesos, porque con sólo un marco que adelantara en los relaves y que perdiera menos azogue se le podría hacer partido más ventajoso". 
adelanto de sueldo y abandonar el asiento minero o escapar con una deuda pendiente, pero a pesar de ello siempre se vería perseguido, como le ocurrió a Miguel Párraga, que fue apresado al año siguiente de fugarse, por haber dejado una deuda pendiente en el asiento de Poopó, y conducido preso hasta Huanuni por el administrador del ingenio. ${ }^{68}$

Generalmente, el pago a los trabajadores no se efectuaba totalmente en moneda sino que se realizaba parte en dinero y otra parte en especies que solían consistir en coca, ${ }^{69}$ alimentos de primera necesidad como el pan, chuño, maíz, harina, y a veces ropa. Pero estos productos, muy apreciados por los trabajadores, eran suministrados con sobreprecio o de forma abusiva. Los distintos estudios sobre el tema han puesto énfasis en la falta de capital del minero como determinante para recurrir a esta forma de pago, pero cabrían añadir otros factores igualmente decisivos.

Carlos Contreras, en su estudio sobre Hualgayoc, propone que esta forma de remuneración mixta, parte en plata y parte en género, era además de una estrategia empresarial, una demanda de los mismos trabajadores, porque de no ser así, en una situación de escasez de mano de obra no lo hubiesen admitido los trabajadores. ${ }^{70}$ La documentación encontrada para el caso de Oruro nos sugiere que no debe generalizarse la demanda de los trabajadores sobre esta forma de pago. Concretamente en Oruro, encontramos un gran rechazo y una queja explícita por parte de los operarios respecto al pago en especie. Esto se debía, en gran medida, a que los trabajadores sabían que era una forma de reducir sus salarios y un mecanismo de engaño, abuso y retención. En todo caso, aunque las pulperías de los centros mineros fuesen una de las formas de acceder a ciertos bienes necesarios para la población indígena, por ejemplo la coca, hubo todo un rechazo a la sobrevalorización de su precio, quizás por tener como referencia los precios en el mercado de Oruro y la posibilidad de acceder a estos productos en la misma villa. El pacto entre trabajadores y empresarios sobre el pago en especie cobra mayor sentido en los asientos mineros bastante alejados de los centros comerciales, donde el acceso a ciertos géneros era bastante difícil. Pero ciertos casos nos parece que se salen fuera de este supuesto y demuestran que no podría concebirse este sistema de pago como demanda

68 ANB, Minas, t. 131, núm. IX.

69 Daniel Santamaria opina que para el minero el tráfico de coca constituyó la posibilidad de reclutar y conservar la mano de obra, y de aumentar su rendimiento, de manera que a su actividad básica añadió un activo rol mercantil: "La participación indígena en la producción y comercio de coca, Alto Perú 1780-1810", en La participación indígena en los mercados....

70 Contreras: Los mineros y el Rey, págs. 77-78. 
de los trabajadores de forma generalizada. Por ejemplo, en Potosí, durante una visita de minas en 1765 , los mitayos se quejaban de que se les pagaba parte de su trabajo personal en "chicha y coca" que les estaban obligando a comprar por la fuerza. ${ }^{71}$ También encontramos otros testimonios referentes al pago en productos que no eran de primera necesidad, como fueron las monteras, cigarros y aguardientes. ${ }^{72}$

Es importante tener en cuenta que a la mano de obra estacional, que acudía a las minas o ingenios para conseguir dinero destinado a sus tributos u otras necesidades, no le interesaba el pago en especie. En ocasiones, también eran los propios caciques los que enviaban a las minas a sus tributarios para conseguir dinero. Esta misma situación era la del originario de Sacaca que fue hasta el ingenio de José Cazaos para pagar una deuda a su cacique y se quejaba de que, después de 15 días, "no pudo conseguir el dinero de su personal trabajo". ${ }^{73}$ Aun en el caso de que los indígenas demandasen o aceptasen el pago en productos a los que dificilmente pudiesen tener acceso, no estaban dispuestos a pagar un sobreprecio o a ser coaccionados a través de las deudas. El desacuerdo con este sistema de pago por el abuso que implicaba, quedaba reflejado en el interrogatorio realizado a los distintos operarios de los ingenios de las tres riberas. Una de las preguntas planteadas abordaba directamente el tema y, por supuesto, sus respuestas fueron de total rechazo:

"Digan si es público y notorio el engaño grave y doloroso de nuestro personal trabajo, y si por el jornal diario y al cabo de la semana nos dan nuestros avíos y socorros en efectos comestibles e inútiles de ropa, recargándonos excesivos precios, de modo que un medio real de coca nos reputan por dos reales, siguiendo esta graduación en todos los demás víveres, tal que no nos soporta la personal manutención cuanto es más la de nuestras mujeres, hijos y familias". ${ }^{74}$

Según los testimonios encontrados, no siempre se trataba de que el trabajador adquiriese voluntariamente las mercancías de la pulpería de la mina o el ingenio, ante la necesidad de cobrar el sueldo, sino que eran obligados a tomar a cuenta del jornal una cantidad estipulada de mercancías. Sirva como ejemplo la correspondencia entre el minero Manuel Herrera

71 AGI, Charcas, 480. Informe de la visita practicada en 1765 por el gobernador de Potosí, Jaime San Just.

72 ANB, Minas, t. 151, año 1790.

73 ANB, Minas, t. 131, años 1793-1797.

74 Ibídem, t. 131, núm. 16. 
y su administrador, donde se comentaba la distribución de los productos y precios, de esta manera:

"dicho chuño, maíz, y harina, se repartió a toda la gente de aquí, al hornero a 4 reales y a los repasiris y mortiris a tres reales". ${ }^{75}$

En otra de las cartas, fechada en 1781 —año de la sublevación indígena-, el administrador hacía referencia al minero del cambio de actitud de los operarios:

"ni aun al trabajo no vienen tan temprano, ni lo trabajan con voluntad, sino están hablando contra nosotros, pues ayer a los horneros les dijimos que llevasen doce reales de coca y dijeron que no podían llevar tanto, sino seis...que ahora es otro tiempo ya, y no es antes para que les estemos dando asî". ${ }^{76}$

Las pulperías de los ingenios y el pago en géneros no eran solamente una estrategia para reducir costos, sino también un negocio del que los mineros y azogueros sacaban beneficios. La prueba está, no sólo en el sobreprecio de los productos del que se quejaban los trabajadores, sino en la existencia de algunas de las cláusulas, recogidas en los acuerdos para formar compañías entre distintos empresarios, donde se especificaba el reparto de los beneficios que generaban el abastecimiento de género a los trabajadores. Por ejemplo, en la compañía formada entre los mineros Esteban Bustillos, Manuel Serrano y el azoguero Diego Flores, se estableció la siguiente cláusula:

"Es calidad y condición expresa que en cuanto a las utilidades de la coca y demás menesteres que se hubiese de expender entre la gente que trabajase en dicha mina, haya de ser partida entre los compañeros sin novedad alguna". ${ }^{77}$

Por lo general, los dueños de minas e ingenios poseían también haciendas de las que se proveían de estos insumos o hacían grandes compras al por mayor de estos productos, entre los que se encontraba la coca proveniente de las Yungas o bayetas del Cuzco. Se dieron casos de azogueros que tenían propiedades en Yungas desde donde traían su propia coca. Pero aun así, estaría lejos de asemejarse a la situación descrita por Brading de las grandes empresas mexicanas que poseían una gran autosuficiencia

75 AGI, Charcas, 605. Papeles embargados a Manuel Herrera.

76 Ibídem. Carta fechada en 1781.

77 ACSJ. Oruro, año 1771. 
de insumos. ${ }^{78}$ El pago en géneros también estaba muy determinado por la escasez de moneda en la zona y por las imposiciones del crédito a los mineros, que se realizaban generalmente parte en dinero y parte en productos mercantiles, proyectándose la situación al pago de los trabajadores. Los habilitadores o aviadores llevaban ventajas en el sobreprecio de los productos con que habilitaban al minero y, como afirma Contreras ${ }^{79}$ era una forma de proteger su inversión, asegurando el buen uso del capital invertido. De todas formas, este tipo de remuneración, bastante generalizado en todos los centros mineros a fines del XVIII, no responde exclusivamente a la minería andina, americana ni colonial, pues se estaba practicando también en las minas de Gran Bretaña. ${ }^{80}$ Se trataba, en cualquier caso, de una estrategia de los empresarios para reducir costos y controlar la mano de obra. Tandeter reconoce el endeudamiento de los trabajadores que sacaban los efectos a crédito de las pulperías, sobre todo coca, chicha y aguardiente, a precios "que duplicaban los prevalecientes en la ciudad"; el endeudamiento se daba tanto en los trabajadores libres como entre los mitayos, pero afectaba a los menos cualificados. ${ }^{81}$

En el virreinato novohispano, encontramos referencias al pago en especies como principal base del peonaje por deudas. Concretamente, en las minas de Santa Eulalia, donde — -según Hadley—, la causa principal de este tipo de remuneración era la carencia de capital de los mineros y azogueros, que dependían del crédito de los habilitadores. Los trabajadores, aunque manifestaron sus quejas, compensaban la falta de dinero con la venta de la pepena o partido a los rescatadores. Claro que cuando se rompía esta situación de equilibrio se abría un claro conflicto, como lo demostraron las huelgas de los trabajadores en 1730 en Santa Eulalia, ${ }^{82}$ o la producida en la mina de Real de Monte en $1766 .^{83}$

78 Brading: Mineros y comerciantes..., cap. IV.

79 Contreras: Los mineros y el Rey, págs. 78-80.

80 Los trabajadores del carbón y del hierro, de Gales y Midlans, estaban siendo pagados con productos a precios sobrevalorados, por lo que emprendieron una denuncia en 1816. Se estaba obligando a los trabajadores a aceptar 2/3 del salario en especie. El Parlamento prohibió esta práctica, pero en 1832 había testimonios de que todavía continuaba. Véase And y Hammon: The Town Labourer (17601832), V, I, Londres, 1949, pág. 75.

81 Tandeter: "Los trabajadores mineros...", pág. 61.

82 Hadley: Minería y sociedad en el centro minero..., págs. 184-201. Este autor considera que el valor de la pepena era seguramente superior al del salario y al de la ración alimenticia.

83 El conde de Regla argumentó que un $37,5 \%$ de la plata producida en su mina pasaba por manos de trabajadores. Para el caso del "tumulto" de los trabajadores de Real de Monte por la supresión del partido, véase Velasco: "Los trabajadores mineros...”, pág. 290. 


\section{Conclusiones}

El abuso del que se quejaron los trabajadores de Oruro a fines del siglo XVIII y el empeoramiento de sus condiciones laborales, fue consecuencia de las presiones de los mineros y azogueros que se encontraron con mayores dificultades para conseguir mano de obra. La disminución de la necesidad de emplearse en la minería por parte de los indígenas que vivían de la tierra, tanto en comunidades como en haciendas, y la crisis minera de fines de siglo, que redujo la capacidad de los empresarios, propiciaron una serie de estrategias agresivas como las levas de indios.

Pero más allá de esta coyuntura, consideramos importante insistir en una diferencia o división dentro de lo que se consideraría el grupo que conformaba la mano de obra minera en Oruro; por una parte se encontraría el sector más cualificado, mejor pagado, y más heterogéneo en cuanto condición étnica y social y, por otra, un sector mal pagado e incluso, en gran medida, compelido para el trabajo más duro. Este grupo no tenía la actividad minera como único recurso, por lo que los azogueros se podían permitir el no asegurar, a través del salario, su subsistencia. En este caso, podríamos señalar que el sector agroganadero o la economía campesina - como la denomina Assadourian- ${ }^{84}$ estaba subsidiando la minería en la región. Quizás no pueda equipararse al nivel que llegaba el transvase de excedentes de las comunidades indígenas hacia Potosí o los centros donde existían indios de repartimiento, pero igualmente las haciendas estaban proporcionando a bajo costo tanto la mano de obra como las mercancías y productos destinados al pago de salarios.

84 Assadourian, en su análisis sobre la mita potosina, afirma que la economía campesina financiaba a la economía minera, rebajando los costos de producción y sufragando parte de los medios de vida indispensables para la reproducción de los trabajadores compulsivos: "La producción de la mercancía dinero en la formación del mercado interno colonial”, pág. 266. 